\title{
THE INFLUENCE OF MIDDLE-EAR ACTIVITY ON AUDITORY THRESHOLD SHIFTS INDUCED BY NOISE
}

\author{
Major P. F. BRASHER, M.B., F.R.C.S., D.L.O., R.A.M.C. \\ Surgeon Commander R. R. A. COLES, M.B., B.Chir., D.L.O., R.N. \\ Dr. M. A. ELWOOD, Ph.D. \\ Miss H. M. FERRES, M.Sc.
}

SUMMARY: Variations in temporary threshold shifts (TTS) induced by octave-band noises centred on $1000 \mathrm{~Hz}$ and $4000 \mathrm{~Hz}$ and by impulses were examined in relation to four measurements of middle-ear muscle activity in 16 normal-hearing subjects. These latter measures comprised acoustic reflex (AR) threshold, initial AR strength, AR strength after two minutes of continuous stimulation, and examination of the degree to which the muscles contracted in anticipation of loud impulses. Some correlations appeared between one TTS measurement and another, and between one AR measurement and another, but there were none between TTS and AR or anticipatory contraction. These results, together with the findings of other workers, lead the authors to conclude that middle-ear muscle activity has little importance with respect to individual variations in susceptibility to moise-induced TTS or to reduction of auditory hazard in many noise exposure situations.

When the middle-ear muscles contract in reflex response to acoustic stimulation the resulting impedance changes modify the acoustic transmission properties of the middle ear. The effect is believed from cochlear microphonic reduction studies in animals (Simmons, 1959, Price, 1966) to result in attenuation of sounds in the frequency range below $2000 \mathrm{~Hz}$. In man, the same conclusion is reached by less direct evidence from attenuation caused by voluntary middle-ear muscle contraction (Smith, 1943, Reger, 1960), from measurement of contralateral remote masking (Ward, 1961) which is probably at least partly due to accoustic reflex (AR) activity, and from numerous temporary threshold shifts (TTS) experiments in which AR activity seems the probable explanation of reduced TTS from exposure to noise in the low or middle frequency rànge (e.g. Ward, 1962, 1965a, Cohen, Kylin and LaBenz, 1966).

With impulsive noises, however, the situation is different. The latency of response of the faster-acting stapedius muscle, which can be as short as 10 msec according to

Major P. F. Brasher. Now at Ear, Nose and Throat Department, British Military Hospital, Rinteln, B.A.O.R., was attached to the Army Personnel Research Establishment, Farnborough, Hants during the period of this study.

Surgeon Commander R. R. A. Coles. Institute of Naval Medicine, Alverstoke, Hants, also attached to the Audiology and Human Factors Group, Institute of Sound and Vibration Research, University of Southampton, Hants.

Dr. M. A. Elwood. Head of Physiology 'A' Division, Army Personnel Research Establishment, Farnborough, Hants.

Miss H. M. Ferres. Head of the Statistics Section, Royal Air Force Institute of Aviation, Farnborough, Hants. 
the human electromyographic studies of Perlman and Case (1939) and the animal cochlear microphonic studies of Galambos and Rupert (1959), is far too long for the reflex to have much protective value in most cases of exposure to discrete impulses. However, there are situations where it can reduce the TTS or permanent threshold shifts (PTS) resulting. For instance, if impulses are repeated within intervals of 2 seconds (Ward, 1962) or occur very rapidly as in machine-gun fire (Murray and Reid, 1946, Reid, 1946) when the next impulse arrives before the reflex contraction to the previous one has subsided, then the auditory effect from a given number of impulses is reduced. Or, if the impulses are deliberately preceded (Fletcher and Riopelle, 1960) or accompanied (Cohen, Kylin and LaBenz, 1966) by other noises of less hazardous but still reflex arousing potential, then the TTS may be reduced. Or, if long experience of noise exposure has resulted in a raised initial reflex threshold and in an increased tonic resting contraction in the muscles (Mendelson, Fletcher and Loeb, 1963) or in a decreased strength of reflex contraction (according to Terkildsen, 1960), or if a tonic contraction of the tensor tympani muscle observable as a change in the angle of the handle of the malleus can persist four hours after noise exposure (Roydhouse, 1968), then again less TTS might result from impulse noise.

Finally, there is a suggestion that if intense gunfire types of impulse occur at precisely known times, as would occur when a soldier fires his own rifle, then the firer may contract his middle-ear muscles in anticipation of the noise (Djupesland, 1965) and thus possibly produce some protective effect (Reid, 1946, Coles, 1962).

The fact that the AR may under certain circumstances afford some protection against noise makes it possible that the wide variations in susceptibility to TTS, which are usually assumed to be closely related to susceptibility to permanent noise-induced hearing loss, may be mediated by corresponding variations in the efficiency of the reflex. The latter may be measured by such means as the reflex threshold or, probably more effectively (Simmons, 1963), by the degree to which the reflex response is sustained. On the other hand, the limitations of the AR as to the frequency of attenuation in the case of steady-state noise and as to latency in the case of impulse noise make it unlikely to be a major factor in noise susceptibillity, which Ward (1965b) has recently concluded to be a multi-factorial phenomenon.

The principal purpose of the investigation to be described was to obtain information on the possible correlations between individual variations in middle-ear muscle activity and susceptibility to TTS.

\section{Methods}

Four measures of middle-ear muscle activity and three sets of TTS measurements were made in each of a group of 16 young men whose hearing was within the limits of normality (defined for this purpose as hearing levels re the International Organisation for Standardisation (I.S.O.) normal threshold that were no greater than $20 \mathrm{~dB}$ from 250 to $4000 \mathrm{~Hz}$, or $30 \mathrm{~dB}$ at 6000 and $8000 \mathrm{~Hz}$ ) and who, even within these limits, had no sign of impaired middle-ear function.

\section{AR measurements}

The basic instrument used for all measurements of middle-ear muscle activity was the Madsen ZO 61 Acoustic Impedance Meter described by Terkildsen and Scott Nielsen 
(1960). With this, changes in ear impedance, such as from a middle-ear muscle contraction, are indicated visually as meter deffections. In our case the voltages causing the meter deflections were recorded on one channel of an Elema "Mingograph" 24B 2-channel pen recorder and amplifier system. The pure tones of the ZO 61 were replaced as AReliciting stimuli by the noises later used for inducing TTS, and their temporal characteristics were recorded simultaneously on the second channel of the pen recorder. A block diagram of the apparatus is shown in Fig. 1.

Tape-recorded octave-band noises centred on $1000 \mathrm{~Hz}$ and $4000 \mathrm{~Hz}$ were used for eliciting the AR, and, later, blank pistol shots fired by the subject provided another form of middle-ear muscle stimulus. The acoustic output of the TDH-39 earphones, both for AR stimulation (one earphone only) and for TTS production (both earphones), was measured with a Bruel and Kjaer precision sound level meter and artificial ear employing a N.B.S. 9-A coupler. The output of the Ferrograph tape recorder and the Amplivox attenuator was adjusted to the correct level before each experimental session and the energising voltage was monitored thereafter by the voltmeter built into the attenuator. The detailed spectra of the octave-band noises emitted from the TDH-39 earphones used for AR stimulation and noise exposure are shown in Fig. 2. The Dawe sound level meter was used purely as a convenient way of energising channel 2 of the pen recorder to record the timing of the stimulus during AR measurements, when No. 2 earphone or the pistol-shot provided the noise stimulus for this purpose.

With such a complex impedance involved, it is not possible to say exactly which elements of the ear's acoustic impedance are concerned when a change of impedance is indicated by the ZO 61 meter. However, it is probably a fair assumption that the extent of impedance change indicated by the ZO 61 meter deflection is closely related to the amount of attenuation afforded, and the same assumption appears to have been taken in a somewhat similar study recently performed by Johansson, Kylin and Langfy (1967).

With each octave-band noise in turn the following AR measurements were made in each ear separately:-threshold (measured in $5 \mathrm{~dB}$ steps provided by the Amplivox attenuator), initial strength resulting from stimulation at $105 \mathrm{~dB}$ s.p.l., as measured by the extent of the deflection in the impedance recording (the ZO 61 and pen recorder being kept at a constant sensitivity setting), and strength of $A R$ at the end of a continuous two-minute stimulation at $105 \mathrm{~dB}$ (this was followed by a second but brief stimulus at $105 \mathrm{~dB}$ to check that the initial magnitude of impedance change could be repeated, any fatigue of the reflex being abolished by even a short quiet interval, thus indicating that any change in baseline of the recording had not "masked" part of the AR that remained after two minutes continuous stimulation).

An example of the AR recording is shown in Fig. 3.

\section{Measurements of anticipatory middle-ear muscle contraction}

An attempt was made to ascertain the degree to which the subjects tended to contract their middle-ear muscles in advance of their firing the pistol. Shots were fired by the subject at regular intervals of about five seconds. Measured with a cathode-ray oscilloscope, each shot produced a noise of peak level between 145 and $155 \mathrm{~dB}$ according to the subject's tolerance of nearness of the pistol to his ear, and of pulse envelope that in the reverberant firing conditions took about $105 \mathrm{msec}$ to fall $20 \mathrm{~dB}$. Although this peak level was below the $160 \mathrm{~dB}$ that reaches the ears of a firer of the rifle type used for 


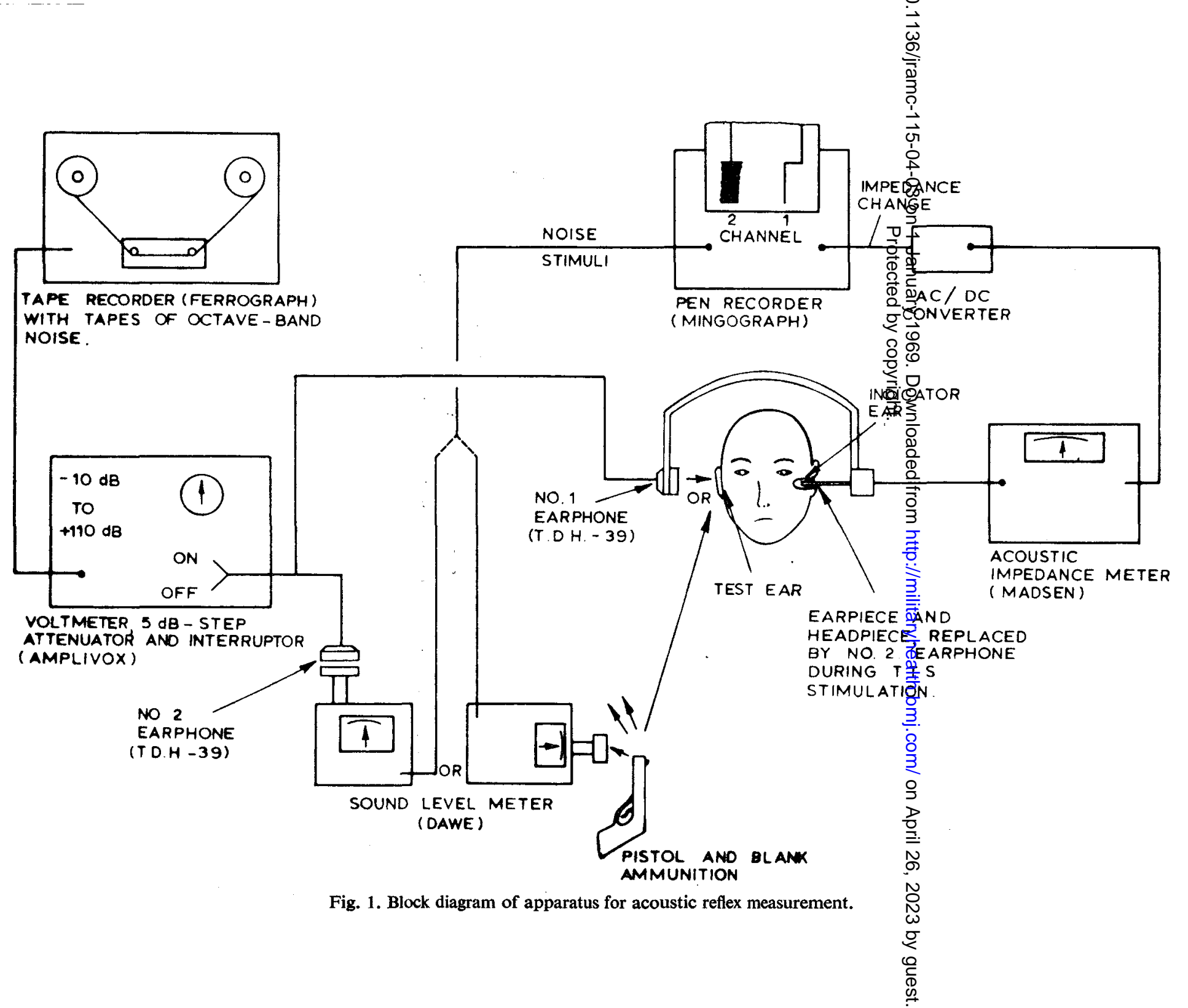




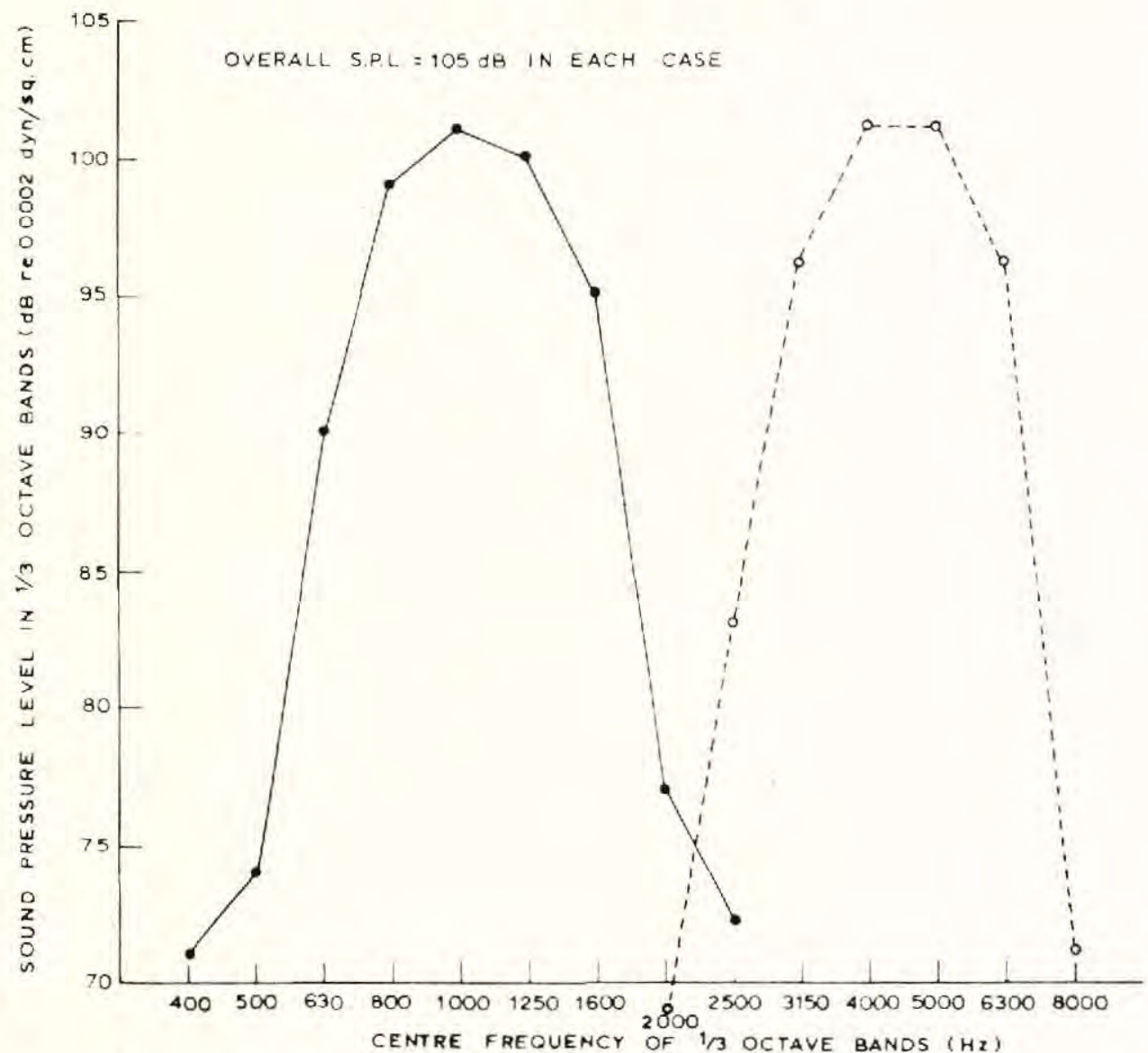

Fig. 2. Frequency spectra of the $1000 \mathrm{~Hz}$ and $4000 \mathrm{~Hz}$ octave-band noises employed.

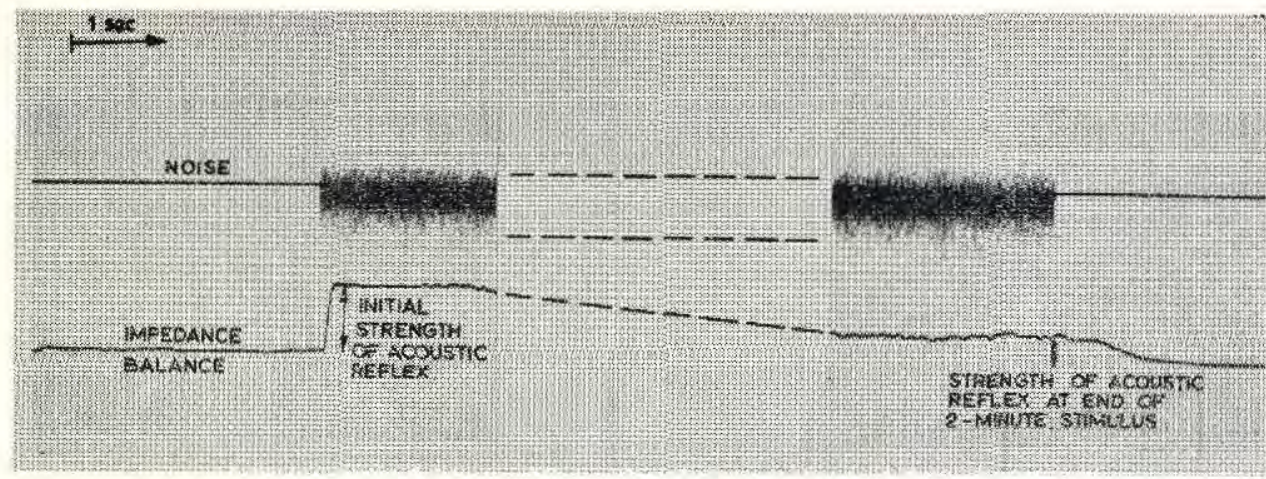

Fig. 3. Example of acoustic reflex response from $1000 \mathrm{~Hz}$ octave-band noise.

the field measurements of impulse-noise susceptibility, the duration was much Ionger, and the pistol shots were considered by the subjects to be of similar loudness or louder. 
An anticipatory contraction was judged to have taken place when there was a change of impedance in advance of the pistol shot and/or a change of impedance occurring with an unexpected misfire (the fourth, fifth or sixth place in the second six-shot magazine to be fired was deliberately left empty for this purpose), the change in the latter case being either in advance of the associated click or too early to be an AR. Unlike the pistol shot which produced a microphonic effect derived from the headpiece of the apparatus (Fig. 4a), the click of a misfire did not produce a microphonic effect and so any anticipatory impedance change was more easily seen on the recording in this case.

In Fig. 4a are shown earlier observations by which it was possible to identify the timing and character of changes of impedance due to microphonic effects and to an AR: it should be realised, however, that the recordings of the impulses on the upper trace were done purely for timing the onset of the impulses, and that they did not provide a measure of the peak levels or durations of these noises.

Of further interest was the observation that, although a randomly occurring misfire click was not sufficiently loud to produce an AR (Fig. 4b), a click in place of an expected shot sometimes produced an impedance change of AR-like latency as well as an anticipatory contraction (Fig. 4c), presumably by some form of AR facilitation. Of the 16 subjects, 9 showed an impedance change both before the shots and in time with the click of a misfire, 2 more showed impedance changes from clicks, and 5 appeared not to contract their middle-ear muscles in anticipation of the shots.

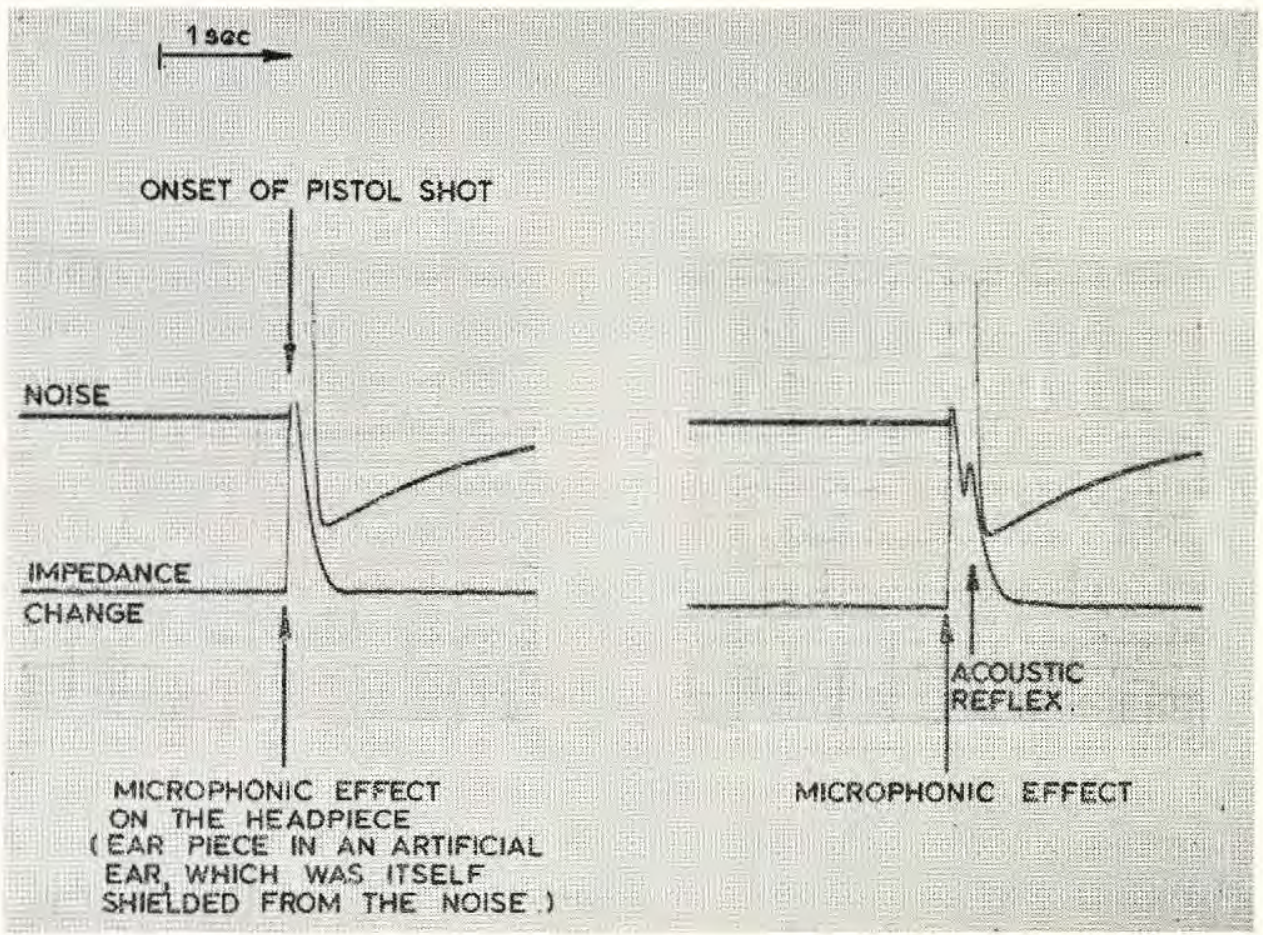

Fig. 4. (a) Relationship between microphonic effects and acoustic reflex in pattern of impedance changes recorded. 


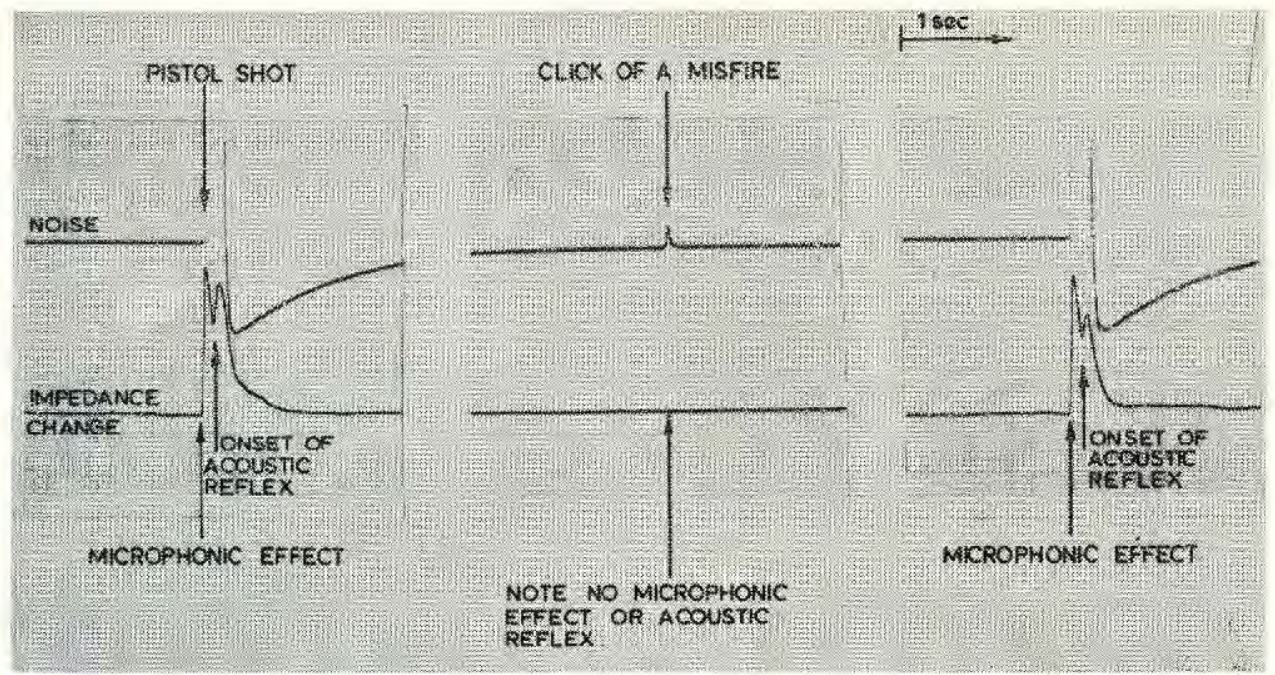

Fig. 4. (b) Acoustic impedance changes in response to shots and misfires fired by an assistant without warnings.

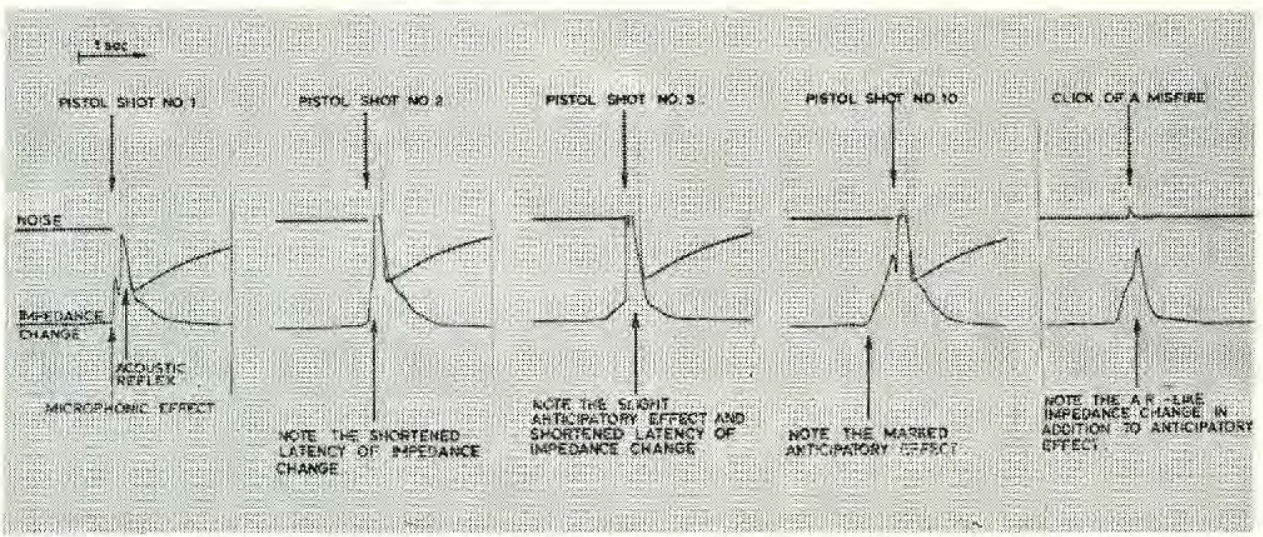

Fig. 4, (c) Acoustic impedance changes in response to shots and misfires fired by the subject.

\section{Octave-band noise TTS measurements}

These were obtained from pre- and post-exposure auditory threshold measurements obtained with a Rudmose ARJ-4 fixed-frequency self-recording audiometer. Postexposure tests commenced after an interval of 2 minutes and were carried out in the following order: $3000 \mathrm{~Hz}$ left, $4000 \mathrm{~Hz}$ left, $6000 \mathrm{~Hz}$ left, $3000 \mathrm{~Hz}$ right, $4000 \mathrm{~Hz}$ right, $6000 \mathrm{~Hz}$ right in the case of the $4000 \mathrm{~Hz}$ octave-band noise exposure, and in a similar manner but at $1000 \mathrm{~Hz}, 2000 \mathrm{~Hz}$, and $3000 \mathrm{~Hz}$ following the $1000 \mathrm{~Hz}$ octave-band noise exposure. Thus retests occupied the period two to five minutes after noise exposure, and the TTS values used in analysis of results were those derived direct from the various exposure-retest intervals within the two to five minutes range, i.e. without correction back to any standard post-exposure interval. The octave-band noise exposures were at $105 \mathrm{~dB}$ s.p.l. for 25 minutes each. 


\section{Impulse noise TTS measurements}

With a rifle producing a peak level at the firer's ears of about $160 \mathrm{~dB}$, each subject fired successively increasing numbers of rounds until a TTS criterion was reached: the latter was $20 \mathrm{~dB}$ TTS at $3000,4000,6000$ or $8000 \mathrm{~Hz}$ in either ear, or $15 \mathrm{~dB}$ TTS at any two adjacent frequencies. If 20 rounds were sufficient for the TTS criterion to be reached, the man was placed by Elwood's classification (Elwood, Brasher and Croton, 1966) into impulse noise-sensitivity Grade I; if a further 40 rounds were needed, he went into Grade II; if a further 60 rounds were needed, he went into Grade III; if after this $20+$ $40+60$ rounds of exposure the criterion TTS was still not reached, he was classified as Grade IV. An Amplivox Model 51 manually-operated battery-powered audiometer was used for the measurements.

\section{Procedure}

Each subject had two experimental sessions, one in the laboratory and one in the field.

The laboratory session occupied three hours and covered initial hearing level measurements, followed by $4000 \mathrm{~Hz}$ octave-band noise AR and TTS measurements in each ear, and then similar measurements with the $1000 \mathrm{~Hz}$ noise. The $4000 \mathrm{~Hz}$ AR and TTS measurements preceded the $1000 \mathrm{~Hz}$ ones, because the TTS from the $4000 \mathrm{~Hz}$ noise would not extend down to the frequencies that were affected maximally (1000 and 2000 $\mathrm{Hz}$ ) by the subsequent $1000 \mathrm{~Hz}$ noise, whilst any high-frequency TTS from the $1000 \mathrm{~Hz}$ noise would occur after measurements of the $4000 \mathrm{~Hz}$ noise exposure effects had been completed. To round off the laboratory session, the impulse-noise anticipation observations were carried out, but with only one ear in this case.

The field session was briefer and was restricted solely to measuring TTS after exposure to the rifle noise.

\section{Results}

Attempts to correlate the various measurements and observations fall into three categories:- comparison of TTS from different stimuli, comparison of TTS and AR, and comparison of AR from different stimuli.

\section{Comparison of TTS with TTS}

In comparing TTS from the two octave-band noises, the maximum shift at any one frequency was considered for each ear. The correlation coefficients were +0.40 for the left ear (not significant, $\mathrm{df}=14$ ) and +0.01 for the right ear. When both left and right ears were considered together but as separate units, the correlation coefficient was +0.29 (not significant, $\mathrm{df}=30$ ).

The correlations between left and right ears in respect of TTS from the two noises were also calculated. They were $+0.53(\mathrm{P}=0.05, \mathrm{df}=14)$ for the $1000 \mathrm{~Hz}$ octave-band noise and +0.25 (not significant) for the $4000 \mathrm{~Hz}$ one. Similarly, in a series of 32 experiments with 49 subjects, Ward (1968) reported the highest left-to-right ear correlation $(+0.78)$ in TTS at $1200 \mathrm{~Hz}$ from a $700 \mathrm{~Hz}$ pure-tone noise and the lowest correlation $(+0.21)$ in TTS at $4000 \mathrm{~Hz}$ from a $2800 \mathrm{~Hz}$ pure-tone noise.

In comparing TTS from each octave-band noise with the impulse-noise grading, the maximum shift in either ear at any frequency was considered. The data can best be 
expressed in tabular form (Table I). No significant relationship between susceptibility to the impulse noise and either of the steady-state noises was demonstrated.

\section{Comparison of TTS with AR}

With the octave-band noises, the principal measure of TTS that was used for analysis was the maximum occurring at any of the audiometric frequencies tested. In addition, because attenuation produced by the AR is known to decrease for frequencies above $1000 \mathrm{~Hz}$, the TTS at $1000 \mathrm{~Hz}$ alone was also considered in the case of the 1000 $\mathrm{Hz}$ octave-band noise. The AR measurements considered were threshold, initial strength and residual strength after a two-minute period of continuous stimulation with the octave-band noise concerned.

Treating separately the reflex responses to acoustic stimulation of each ear and the TTS in the same ear, no significant correlations were found for either of the octave-band noises in any comparison between TTS and AR threshold, initial strength or residual strength after two minutes continuous stimulation. Examination of the extreme cases, of TTS-susceptibility and of TTS-resistance, did not indicate any relationships to the AR measurements either.

With regard to sensitivity to impulse noise, it might be suggested that a very sensitive response, such as the rifle Grade I, might be dependent upon having a high AR threshold, a low initial AR strength, a failure of anticipatory middle-ear muscle contraction or upon any combination of these factors. It was impossible with the data available to show any significant relationships between impulse-noise sensitivity and any of the middle-ear muscle activity factors studied, and it would appear that even if, with more data, a relationship could be established it would be slight. Thus, there appeared to be no indication that could be taken to support a close dependence of the sensitivity to impulse noise upon these middle-ear muscle activity parameters alone.

\section{Comparison of $A R$ with $A R$}

No correlation could be demonstrated between anticipatory middle-ear muscle contractions and AR responses from the octave-band noise stimuli. On the other hand, the relationships between the different measures of AR response provided a number of correlations which are detailed in Tables II and III.

These show that in selecting a measurement of AR there is little to choose between measurements of threshold and initial strength (except to note the expected inverse relationship between the two, as found also by Terkildsen (1960), and that the amount of response remaining after two minutes of continued stimulation tends to be largely a function of the initial strength. On average, as measured in the manner described here, the strength of the AR adapted less rapidly from low-frequency stimuli than from highfrequency stimuli (as found previously by Lorenté de No (1935) and by Johansson, Kylin and Langfy (1967). The reduction over the two-minute stimulation was to a factor of 0.6 of the initial value with the $1000 \mathrm{~Hz}$ octave-band noise and 0.2 with the $4000 \mathrm{~Hz}$ one. In most cases, the majority of the adaptation took place in the first 20 to 30 seconds, as noted also by earlier investigators (Lorenté de No, 1935, Wersäll, 1958, Dallos, 1964). On the other hand, the AR from the $1000 \mathrm{~Hz}$ octave-band noise had non-significantly a higher average threshold ( $94 \mathrm{~dB}$ s.p.l.) and smaller average magnitude (17 $\mathrm{mm}$ pen deflection) from the $105 \mathrm{~dB}$ stimulus than was the case $(92 \mathrm{~dB}$ and $19 \mathrm{~mm}$ ) 
Table I

Comparison of TTS from steady-state and impulse noises

\begin{tabular}{|c|c|c|c|c|}
\hline \multirow{3}{*}{$\begin{array}{l}\text { Impulse noise-induced } \\
\text { TTS grading }\end{array}$} & \multicolumn{4}{|c|}{$\begin{array}{l}\text { Maximum TTS (dB) from } 25 \text { minutes of } 105 \mathrm{~dB} \text { octave-band noise } \\
\text { centred on: }\end{array}$} \\
\hline & \multicolumn{2}{|l|}{$1000 \mathrm{~Hz}$} & \multicolumn{2}{|l|}{$4000 \mathrm{~Hz}$} \\
\hline & Individual maxima & Mean & Individual maxima & Mean \\
\hline $\begin{array}{l}\text { I (most susceptible) } \\
\text { II } \\
\text { III } \\
\text { IV (least susceptible) }\end{array}$ & $\begin{array}{l}9,14,17,18,26,27, \\
11,14,17,31 \\
14,19 \\
10,10,15,15\end{array}$ & $\begin{array}{l}18.5 \\
18.2 \\
16.5 \\
12.5\end{array}$ & $\begin{array}{l}13,15,19,27,33,39 \\
10,15,16,35 \\
23,39 \\
1,13,19,19\end{array}$ & $\begin{array}{l}24.3 \\
19.0 \\
31.0 \\
13.0\end{array}$ \\
\hline
\end{tabular}

Table II

Comparison of AR : Between different stimuli

\begin{tabular}{l|l}
\hline From 1000 and $4000 \mathrm{~Hz}$ octave-band noise stimuli & Correlation coefficient \\
\hline AR threshold & $+0.55 \star$ \\
AR initial strength & $+0.78 \dagger$ \\
AR 2-minute strength & negligible \\
\hline
\end{tabular}

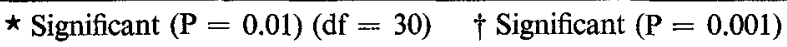

Table III

Comparison of AR : Between different measures

\begin{tabular}{|c|c|c|}
\hline $\begin{array}{l}\text { Octave-band } \\
\text { noise stimulus }\end{array}$ & AR comparison & Correlation co-efficient \\
\hline $\begin{array}{l}1000 \mathrm{~Hz} \\
4000 \mathrm{~Hz}\end{array}$ & $\begin{array}{l}\text { Threshold vs initial strength } \\
\text { Threshold vs } 2 \text {-minute strength } \\
\text { Initial vs } 2 \text {-minute strength } \\
\text { Threshold vs initial strength } \\
\text { Threshold vs } 2 \text {-minute strength } \\
\text { Initial } \\
\text { vs } 2 \text {-minute strength }\end{array}$ & $\begin{array}{l}-0.66 \dagger \\
\text { negligible } \\
+0.90 \dagger \\
-0.23 \mathrm{NS} \\
\text { negligible } \\
+0.69 \dagger\end{array}$ \\
\hline
\end{tabular}

$\uparrow$ Significant $(\mathrm{P}=0.001)(\mathrm{df}=30)$

Table IV

Comparison of left to right ears : Between AR measures

\begin{tabular}{c|l|c}
\hline $\begin{array}{c}\text { Octave-band } \\
\text { noise stimulus }\end{array}$ & \multicolumn{1}{|c}{ Left to right ear comparison } & \multicolumn{1}{c}{ Correlation coefficient } \\
\hline $1000 \mathrm{~Hz}$ & AR threshold & $+0.67 \star$ \\
& AR initial strength & $+0.81 \dagger$ \\
$4000 \mathrm{~Hz}$ & AR 2-minute strength & $+0.69 \star$ \\
& AR threshold & $+0.63 \star$ \\
& AR initial strength & $+0.55 \star$ \\
& AR 2-minute strength & $+0.67 \star$ \\
\hline
\end{tabular}

$\dagger$ Significant $(\mathrm{P}=0.001)(\mathrm{d} f=14) \quad$ † Significant $(\mathrm{P}=0.05) \quad$ * Significant $(\mathrm{P}=0.01)$

with the $4000 \mathrm{~Hz}$ octave-band noise; these data, like those of McRobert, Bryan and Tempest (1968), do not support the universally better reflex from low frequency noises reported by Djupesland, Flottorp and Winther (1967), but which was probably an artefact due to their use of hearing level and sensation level units rather than of sound pressure level. 
The correlations between left and right ears in respect of the AR measures were also calculated, and are given in Table IV.

\section{Discussion}

Middle-ear muscle activity and TTS from impulse noise

In spite of the poor test-retest repeatability in TTS from a given impulse noise (Hodge and McCommons, 1966) and of the rather poor correlation between TTS susceptibilities from different impulse noises (Elwood, Brasher and Croton, 1966), the lack of any correlation here, firstly, between presence or absence of anticipatory middleear muscle contraction and any of the measures of AR and, secondly, between anticipatory middle-ear muscle contraction and the grading of susceptibility to impulse noiseinduced TTS (where the subjects fired the rifle and consequently may have anticipated the noise) suggests that neither degree of anticipation nor any other aspect of AR function is likely to be a factor of much importance in defining susceptibility to hearing loss from intermittent short-duration impulse noises.

On the other hand, in soldiers with relatively high hearing levels at 3000 and 4000 $\mathrm{Hz}$ (presumably impulse noise-induced effects) Hecker and Kryter (1965) showed an increased strength of AR resulting from a white noise stimulus. This contradiction with the apparent correlation between high-tone hearing loss and elevated AR threshold reported by Coles (1962) illustrates further, perhaps, the doubtfulness of any important correlation between middle-ear muscle functions and development or presence of noiseinduced hearing loss, especially where discrete high-intensity impulse noises are involved. In this conclusion, at least, the authors are in agreeement with Hecker and Kryter.

\section{$A R$ and TTS from steady-state noise}

In our study, we found no correlation between any of our measures of middle-ear muscle activity and the TTS resulting from exposure of individuals to prolonged steadystate noise or to discrete impulses. Whilst this does not mean that such activity has no importance in defining individual noise susceptibility, it does suggest that these particular measures and measurement techniques have little practical importance in this respect and as far as these noises are concerned.

On the other hand, in many of the experiments of Ward and his various colleagues and of Fletcher, Loeb and others at United States Army Medical Research Laboratories, Fort Knox, there can be little doubt concerning the author's interpretations that the reduced TTS's found in many of their experimental situations were due to AR effects. More recently, too, Cohen, Kylin and LaBenz (1966) have shown that under certain circumstances TTS from impulses can be reduced by adding steady-state noise to the fatiguing stimulus, and vice versa. This finding is very important in contradiction of the more usual warning, given in damage risk criteria and in other communications (e.g. Dieroff, 1966), against the extra hazards believed hitherto to be associated with impulsive components in the noise; again, the most probable explanation is the AR.

\section{Correlations between TTS from different noises}

Whilst it was not possible to demonstrate any association between susceptibilities to the impulse and steady-state noises, the incidence shown in Table I of some higher values of steady-state noise TTS in Grade I and II subjects suggests that with a consider- 
ably larger sample some low-order association between TTS from the two types of noise might be demonstrable.

This is in agreement with Cohen, Kylin and LaBenz (1966) who found several significant correlations between TTS from impulses and steady-state noises and concluded that "the ear has the same relative degree of vulnerability to TTS from the two types of noise". On the other hand, Fletcher and Loeb (1965) observed no correlations in TTS at the same test frequency between two octave-band noises, and only one significant correlation between any of the octave-band noise effects and the TTS from impulses; they concluded that there appeared to be " no general susceptibility factor". Ward (1968) also found no significant correlation in TTS induced by impulses and steady-state noises, and the general conclusion from his extensive study of noise susceptibility was that a large number of factors were involved.

Thus, measurement of TTS from steady-state noise gives little indication of the likely effects of impulse noise or vice versa. It also seems that the TTS from one impulse noise is not an entirely consistent indicator of the TTS to be expected from another impulse noise (Elwood, Brasher and Croton, 1966), possibly due to considerable intrasubject variations in TTS even when the same impulse noise is used (Hodge and McCommons, 1966). With steady-state noises also the correlations of TTS between noises (Fletcher and Loeb, 1965) and the test-retest repeatability of TTS measurements from one noise (Loeb and Fletcher 1962, 1963) are not sufficiently good to justify application of any general noise-susceptibility test or tests as part of a hearing conservation programme. Such tests do have uses in research however, and particularly with impulse noises, for selection of those sufficiently susceptible to yield some TTS and to indicate those needing special precautions against TTS (Rice and Coles, 1965, Hodge and McCommons, 1966); even then, it is advisable to employ for the susceptibility test either the actual noise or one that is at least similar in its general physical characteristics to the noise to be used for the subsequent full-scale experiments.

\section{General}

Of further interest was the fact that, unlike Loeb and Fletcher (1961) who found no correlations, both Cohen, Kylin and LaBenz (1966) and Ward (1967) were able to show definite if limited negative correlations between TTS and contralateral remote masking (CRM), which can be regarded in part as another measure of AR. The correlations were, however, insufficient to be of much practical value. In this respect, it should perhaps be noted that the role of the AR in CRM may itself be very limited: thus, Fletcher and King (1963) and Bilger (1966) have shown CRM to occur in stapedectomised ears, Gjaevenes and Vigran (1967) found a close correspondence in individual subjects between the CRM at onset of a masking noise and the CRM $40 \mathrm{msec}$ after the noise had ceased, which seems a very unlikely event if the AR were a factor of prime importance in CRM. Ward (1967) has likewise found little difference in CRM at onset of a masking noise and that half a second later, and McRobert, Bryan and Tempest (1968) have experimental evidence that the AR accounts for only about 15 per cent of the whole CRM effect in normal ears.

In the paper by Cohen, Kylin and LaBenz it appeared that the amount of impulse noise-induced TTS might also be related to CRM, but this seems to be of even more doubtful importance in view of two other pieces of evidence. First, Ward (1968) reported a lack of correlation between CRM and TTS from impulse noise, as well as negative 
correlations between steady-state noise-induced TTS and both low and high frequency CRM. Second, Mendelson, Fletcher and Loeb, (1963) found that contraleteral threshold shift (a phenomenon similar to CRM) was generally smaller in amount in subjects with marked temporary threshold shift reduction (TTSR) following exposure to impulse noise preceded by an AR-evoking stimulus: that is, the greater the reduction in TTS supposedly the greater the AR causing the reduction, though it is possible that here too, as in the CRM mechanism, the efferent part of the auditory system or an inhibition of auditory centres within the brain stem may be involved.

An experiment with similar apparatus and object to our own has recently been reported by Johansson, Kylin and Langfy (1967). The "in-impedance" of an electroacoustic bridge was recorded in this study also, and the AR latency, rise time and ARadaptation characteristics were compared with TTS resulting from a 15-minute exposure to a 300 to $1200 \mathrm{~Hz}$ band noise. Pure tones and impulse modulated pure tones were used for stimulating the AR, and patterns of AR adaptation similar to those of Fig. 3 were found. Using this technique, in five extreme cases a close correlation was found between TTS and the AR measures, but in the whole group of 50 subjects there was no general tendency towards an association of greater TTS with greater AR adaptation. If we now add the results of our present study, in which both AR threshold and the two-minute AR strength were correlated to some degree with initial AR strength (Table III), but no correlations between AR and TTS were found either in the whole group or in extreme cases, then it would seem that there is remarkably little correlation between most forms of measurement of middle-ear muscle activity and susceptibility to steady-state or impulse noise-induced TTS. It would also appear that adaption of AR occurs at a fairly rapid rate in most individuals and in many steady-state noise conditions.

\section{Conclusion}

It would seem from our own data, and by consensus of opinion on the various other papers discussed, that variations in middle-ear muscle activity have little to do with variations in individual susceptibility to noise damage, at least as far as intermittent short-duration impulses or steady-state noises are concerned. It is relevant therefore to consider what importance, if any, these muscles have in respect of protection against noise. Perhaps the best evidence comes from study of persons in whom the stapedius has been inactivated.

The evidence for a protective effect is based on:-

The attenuation of sounds up to $2000 \mathrm{~Hz}$ caused by AR action.

The explanation afforded by the AR for paradoxical results in numbers of TTS studies.

The increased TTS from low-frequency noise, but not from high-frequency noise, that resulted from the partial paralysis of the middle-ear muscles and elevation of AR threshold following injection of curare (Smith, Loeb, Thomas and Fletcher, 1966), the hyperacusis often reported by patients suffering from Bell's palsy and herpes zoster of the facial nerve.

Scattered case reports referring to recurrence of high-tone hearing loss after noise exposure of stapedectomised persons.

In the last instance the evidence is unconvincing because high-tone hearing loss is apt to occur from time to time as a late sequel of stapedectomy, often without apparent 
cause or noise exposure; moreover, in the other instances quoted the facts of the situation do not necessarily imply that the AR gives much protection against permanent cumulative noise-induced hearing loss.

The evidence against a protective effect is impressive, but in fact nearly all of it relates to the effects of prolonged steady-state types of noise. For instance:-

The TTS studies of Fletcher and King (1963), Steffen, Nixon and Glorig (1963), and Ferris $(1965,1966,1967)$ suggest that stapedectomised patients show a normal distribution of susceptibility to TTS and an average susceptibility that is equal to or less than, but not greater than, the average susceptibility of normal hearing subjects.

The lack of any marked correlation between variations in AR function and TTS, found in this study and elsewhere, is difficult to explain if the middle-ear muscles had much importance in protecting the ear against noise.

The rapid adaptation of the AR to prolonged stimulation, especially noticeable in the case of tonal stimulation (Lorenté de No, 1935, Wersäll, 1958), and the lack of reflex contraction in time to reduce the level of unexpected or irregular impulses, greatly reduce the possible effectiveness of any protective mechanism.

On the other hand, consider the situation where steady-state noise stimulates the reflex between or immediately prior to impulses or where impulses occur in rapid succession, or where impulses or intermittencies or level fluctuations are superimposed on steady-state noise and serve to prevent adaption of the reflex, or where noise of wideband type is so intense that adaption does not occur ( $30 \mathrm{~dB}$ or more above the acoustic reflex threshold (Dallos, 1964)). In these, it seems likely that the AR may still have some protective effect of practical value and that it is with these types of noise that further research on correlation between AR and noise susceptibility should be carried out.

\section{Acknowledgements}

The authors wish to express their gratitude to Dr. E. J. Richards (until recently Director of the Institute of Sound and Vibration Research, University of Southampton) for permission to carry out this study at the Institute. Thanks are also due to $\mathrm{Mr}$. W. $\mathrm{H}$. Richardson (Institute of Naval Medicine) and Mrs. V. M. Priede (I.S.V.R., Southampton) for their technical assistance. The research was supported in part by the Medical Research Council (Grant No. 965/278/C).

\section{REFERENCES}

BILGER, R. C. (1966). " Remote masking in the absence of intra-aural muscles". J. acoust. Soc. Amer. 39, 103-108.

Cohen, A., Kylin, B. and LABenz, P. J. (1966). " Temporary threshold shifts in hearing from exposure to combined impact/steady-state noise conditions". I. acoust. Soc. Amer. 40, 1371-1380.

COLES, R. R. A. (1962). "Some considerations concerning the effect on hearing of noise of small-arms". Proc. 4th Internat. Congr. Acoustics, Copenhagen. Also in: J. roy. nav. med. Serv. 49, 18-22.

Dallos, P. J. (1964). "Dynamics of the acoustic reflex. Phenomenological aspects". J. acoust. Soc. Amer. 36, 2175-2183.

DierofF, H. G. (1966). " The problem of impulse-rich working noise, its measuring, and the hearing losses resulting from it ". Internat. Audio!. 5, 339-343.

D.UPESLAND, G. (1965). "Electromyography of the tympanic muscles in man.". Internat. Audiol. 4, 34-41.

DJUPESLAND, G., FlotTorP, G. and WiNTHer, F. O. (1967). "Size and duration of acoustically elicited impedance changes in man ". Acta oto-laryng.(Stockh). Suppl. 224. P. 220-228.

ElwOOD, M. A., Brasher, P. F. and CrOTON, L. M. (1966). "A preliminary study of sensitivity to impulse noise in terms of temporary threshold shifts". Paper at British Acoustical Society meeting on impulse noise, Southampton, 1966 and submitted to J. Sound. Vib. for publication. Also summarised by Elwood, M. A. (1967). Proc. Roy. Soc. Med. 80, 1124-1125.

FERRIS, K. (1965). "On the temporary effect of industrial noise on the hearing at 4000 c.p.s. of stapedectomised ears ". J. Laryng. 79, 881-887. 
FerRIS. K. (1966). "The temporary effects of 125 c.p.s. octave-band noise on stapedectomised ears". $J$. Laryng. 80, 579-582.

Ferris, K. (1967). " A further study on the temporary effect of industrial noise on the hearing of stapedectomised ears at 4000 c.p.s.". J. Laryng. 81, 613-617.

FLetcher, J. L. and KING, W. P. (1963). " Susceptibility of stapedectomised patients to noise induced temporary threshold shifts". Ann. Otol. (St. Louis) 72, 900-907.

Fletcher, J. L. and LoeB, M. (1965). "Relationships for temporary threshold shifts produced by three different sources ". J. Aud. Res. 5, 41-45.

Fletcher, J. L. and Rropelle, A. J. (1960). "Protective effect of the acoustic reflex for impuise noises ". J. acoust. Soc. Amer. 32, $401-404$.

Galambos, R. and RoBERT, A. (1959). "Action of the middle-ear muscles in normal cats". J. acoust. Soc. Amer. 31, 349-355

GJAeVENES, $K$ : and VigRAN, E. (1967). " Contralateral masking: an attempt to determine the role of the aural reflex ". $J$. acoust. Soc. Amer. 42, 580-585.

Hecker, M. H. L. and KRYTeR, K. D. (1965). "A study of the acoustic reflex in infantrymen". Acta oto-laryng. (Stockh.) Suppl. 207, P 1-16.

Hodge, D. C. and McCommons, R. B. (1966). "Reliability of TTS from impulse-noise exposure", J. acoust. Soc. Amer. 40, 839-846.

Johansson, B., KYLIN, B. and LANGFY, M. (1967) " Acoustic reflex as a test of individual susceptibility to noise: a preliminary report". Acta oto-laryng. (Stockh.) 64, 256-262.

LoEb, M. and FLETCHER, J. L. (1961). "Contralateral threshold shift and reduction in temporary threshold shift as indices of acoustic reflex action". J. acoust. Soc. Amer. 33, 1558-1560.

LOEB, M. and FleTCHER, J. L. (1962). "Reliability and temporal course of temporary and contralateral threshold shifts ". J. Aud. Res. 5, 284-291.

LoEB, M. and FleTCHER, J. L. (1963). "Temporary threshold shifts in successive sessions for subjects exposed to continuous and periodic intermittent noise ".J. Aud. Res. 3, 213-220.

LoRENTE de No, R. (1935). "The function of the central acoustic nuclei examined by means of the acoustic reflex ". Laryngoscope 45, 573-595.

McRobert, H., BRYAN, M. E. and TEMPEST, W. (1968). " The acoustic stimulation of the middle-ear muscles ". J. Sound. Vib. 7, 129:142.

Mendelson, E. S., Fletcher, J. L. and Loeb, M. (1963). " Noise exposure and individual alterations in middle-ear muscle reflex activity". Aerospace Med. 34, 507-513.

Murray, N. E. and Rem, G. (1946). “Temporary deafness due to gunfire ”. J. Laryng, 60, 92-130.

Perlman, H. B. and Case, I. J. (1939). "Latent period of the crossed stapedius reflex in man ". Ann. Otol. (St. Louis) 48, 663-675.

Price, G. R. (1966). "Middle-ear muscle activity in the rabbit. III. Supra-threshold phenomena". J. Aud. Res. 6, 175-180.

REGER, S. N. (1960). " The effect of middle-ear muscle action on certain psycho-physical measurements ". Ann. Otol. (St. Louis) 69, 1179-1198.

REID, G. (1946). "Further observations on temporary deafness following exposure to gunfire ". J. Laryng. 60, 609-633.

RICE, C. C. and Coles, R. R. A. (1965). "Impulsive noise studies and temporary threshold shift". Proc. 5th Internat. Congr. Acoustics, Liège. Ed. D. E. Commins.

Roydhouse, N. (1968). "A survey of engine room noise in the Royal New Zealand Navy ". N.Z. Med. J. 67, 133-140.

Simmons, F. B. (1959). “Middle-ear muscle activity at moderate levels". Ann. Otol. (St. Louis) 68, 1126-1144.

Srmmons, F. B. (1963). "Individual sound damage susceptibility. Role of the middle-ear muscles". Ann. Otol. (St. Louis) 72, 528-547.

SмIтн, H. D. (1943). "Audiometric effects of voluntary contraction of the tensor tympani muscle". Arch. Otolaryng. 38, 369-372.

Smith, R. P., LoEB, M., Thomas, D. M. and Fletcher, J. L. (1966). " The effects of curare on acoustic reflex function". Acta oto-laryng. (Stockh.) 62, 101-108.

Steffen, T. N., Nrxon, J. C. and GloRIG, A. (1963). "Stapedectomy and noise ". Laryngoscope 73, 1044-1060.

TerkILDSEN, K. (1960) "The intra-aural muscle reflexes in normal persons and in workers exposed to intense industrial noise". Acta oto-laryng. (Stockh.) 52, 384-396.

Terkildsen, K. and ScotT Nielsen, S. (1960). "An electroacoustic impedence measuring bridge for clinical use ". Arch. Otolaryng. 72, 339-346.

WARD, W. D. (1961). "Studies on the aural reflex. I. Contralateral remote masking as an indicator of reflex activity". $J$. acoust. Soc. Amer. 33, 1034-1045.

WARD, W. D. (1962). "Effect of temporal spacing on temporary threshold shift from impulses". $J$. acoust. Soc. Amer. 34, 1230-1232.

WARD, W. D. (1965a). "Temporary threshold shifts following monaural and binaural exposure". $J$. acoust. Soc. Amer. 38, 121-125.

WARD, W. D. (1965b). "The concept of susceptibility to hearing loss ". J. Occup. Med. 7, $595-607$.

WARD, W. D. (1967). " Further observations on contralateral remote masking and related phenomena". J. acoust. Soc. Amer. 42, 593-600.

WARD, W. D. (1968). "Susceptibility to auditory fatigue". In Vol. 3 of Advances in Sensory Physiology. Ed. W. D. Neff. Academic Press, New York.

Wersäll, R. (1958). "The tympanic muscles and their reflexes". Acta. oto-laryng. (Stockh.) Suppl. 139, P 1-112. 